\title{
Effects of thermally modified green tea catechins on the oxidative and hydrolytic stability of butter
}

\author{
Magdalena Mika*, Agnieszka Wikiera, Krzysztof Żyła \\ Department of Food Biotechnology, Faculty of Food Technology, University of Agriculture in Krakow, Kraków, Poland; \\ mmika@ar.krakow.pl
}

Received 15 September 2009; revised 9 October 2009; accepted 10 October 2009

\begin{abstract}
Green tea catechins are classified as (-)-epiforms $(2 R, 3 R)$ or (-)-forms $(2 S, 3 R)$ with respect to stereoisomerism. The (-)-forms $(2 S, 3 R)$ in catechin preparations obtained from green tea amounts to approximately $10 \%$ of total catechins, whereas the other $90 \%$ are (-)-epiforms (2R, 3R). High temperature induces the conversion of (-)-epiforms $(2 R, 3 R)$ to $(-)$-forms $(2 S, 3 R)$. This study investigated the effect of catechin preparations containing 10,20 and $30 \%(-)$-forms (2S, $3 R$ ) on the oxidative and hydrolytic stability of butter. For comparison, butter with $\delta$-tocopherol and BHT and butter without stabilizer were analysed. Butter stability was examined under conditions of refrigeration $\left(8{ }^{\circ} \mathrm{C}\right)$ and freezing $\left(-22{ }^{\circ} \mathrm{C}\right)$ and at temperature of $50^{\circ} \mathrm{C}$ and $100{ }^{\circ} \mathrm{C}$. Catechin preparations were more efficient butter stabilizers than BHT and $\delta$-tocopherol. Thermal modification of catechins that led to the generation of $20 \%$ of (-) forms (2S, 3R) improved their antioxidative efficacy, but longer treatment leading to the formation of $30 \%$ of (-) forms (2S, 3R) decreased their antioxidative activity. The hydrolytic stability of butter, however, increased as the amount of (-) forms (2S, 3R) increased.
\end{abstract}

Keywords: Oxidative; Hydrolytic Stability; Antioxidants; Catechins

\section{INTRODUCTION}

In recent years a number of studies have been carried out that have shown a positive effect of green tea on humans, mainly due to polyphonies. Green tea polyphenols have been reported to have antiatherosclerotic [1], anticarcinogenic $[2,3]$ and anti-inflammatory $[4,5]$ effects. Flavan-3-ols (catechins) form the most numerous group of non-fermented green tea polyphenols. The flavan-3-ol molecule comprises two stereogenic centres situated on the $\mathrm{C}$-ring and constituted by the $\mathrm{C} 2$ and $\mathrm{C} 3$ carbon atoms. Tea catechins always have an $\mathrm{R}$ configuration at the $\mathrm{C} 3$ carbon atom. Based on configuration at the $\mathrm{C} 2$ carbon atom, catechins can be classified into two groups: (-) epiforms (2R, 3R) and (-) forms (2S, 3R) [6]. In catechin preparations obtained from tea the main components are (-) epiforms (2R, 3R): (-) epigallocatechin gallate (EGCG), (-) epicatechin gallate (ECG), and (-) epicatechin (EC). At high temperatures and in anaerobic conditions the epimerization reaction results in more (-) epiforms $(2 \mathrm{R}, 3 \mathrm{R})$ being transformed to (-) forms $(2 \mathrm{~S}, 3 \mathrm{R})[7,8]$. Catechins that belong to the (-) forms (2S, 3R) include: (-) gallocatechin gallate (GCG), (-) catechin gallate (CG), and (-) catechin (C). These compounds efficiently limit the absorption of cholesterol $[9,10]$ and lipid hydrolysis products in the digestive tract [11-14]. Ikeda reported that catechin gallates, being (-) forms $(2 \mathrm{~S}, 3 \mathrm{R})$, were most effective in eliminating cholesterol from bile acid micelles [10]. The antioxidative and antiseptic properties of catechins suggest that these compounds could be used as food stabilizers. Moreover, catechin preparations that are rich in (-) forms $(2 \mathrm{~S}, 3 \mathrm{R})$ seem to be ideal stabilizers of high-fat foods that are also high in cholesterol. The aim of this study was to determine the influence of catechin preparations that differed in flavan-3-ols content on the oxidative and hydrolytic stability of butter stored at $8{ }^{\circ} \mathrm{C}$ and $-20{ }^{\circ} \mathrm{C}$ or exposed to the temperature of $50{ }^{\circ} \mathrm{C}$ and $100{ }^{\circ} \mathrm{C}$.

\section{MATERIALS AND METHODS}

\subsection{Thermal Modification of Catechin Preparations}

Catechin solutions $(50 \mathrm{mg} / \mathrm{ml}$ of redistilled water) were prepared from Sigma Polyphenon 60 and subjected to thermal modification at $140{ }^{\circ} \mathrm{C}$ for 40 minutes (preparation $\mathrm{HMC} 1$ ) or 80 minutes (preparation HMC2). Modifications were carried out in Scott tubes under gaseous nitrogen. 


\subsection{Determination of Chemical Composition of Catechin Preparations}

The composition of flavan-3-ols in thermally modified and non-modified (NMC) catechin preparations was determined by the HPLC method as described by Lin [15]. Standards of (-) ECG, (-) EGCG, (-) GCG, (-) CG, (-) C, (-) EC and catechin solutions (diluted 200-fold) were filtered $(0.45 \mu \mathrm{m})$ and injected $(50 \mu \mathrm{l})$ into a LUNA $5 \mathrm{U}$ C18(2) $(250 \times 4.6 \mathrm{~mm})$ chromatographic column. The Phase A elution solution comprised methanol, formic acid and redistilled water (20:0.3:79.7 v/v/v) and phase B was composed of methanol and formic acid $(99.7: 0.3 \mathrm{v} / \mathrm{v})$. Samples were eluted from the column using the following programme: $(0-10 \mathrm{~min}: 100 \%$ of phase $A ; 10-25 \mathrm{~min}$ : $100 \% \rightarrow 90 \%$ of phase A, $0 \% \rightarrow 10 \%$ of phase B, linear gradient; $25-60$ min: $90 \% \rightarrow 70 \%$ of phase A, $10 \% \rightarrow$ $30 \%$ of phase B, linear gradient). Liquids were filtered and degassed. The flow rate was $1 \mathrm{ml}$ per minute and the detection wavelength was $280 \mathrm{~nm}$.

\subsection{Preparation of Butter Samples}

Catechin preparations (NMC, HMC1 or HMC2) were introduced into home-made butter at concentrations of 50, 100, 200 and $400 \mathrm{mg}$ per $100 \mathrm{~g}$ of butter. For comparison, samples of butter stabilized with $\delta$-tocopherol and 3,5-di-tert-4-butylhydroxytoluene (BHT) in $50 \mathrm{mg}$ per $100 \mathrm{~g}$ of butter were used. Butter samples stabilized with catechin preparations of various amounts of different (-) forms (2S, 3R), BHT, $\delta$-tocopherol and a negative control without stabilizer (K.) were stored at $8{ }^{\circ} \mathrm{C}$ for two weeks or at $-20^{\circ} \mathrm{C}$ for four weeks and then were incubated at 50 ${ }^{\circ} \mathrm{C}$ or $100{ }^{\circ} \mathrm{C}$ for one hour. In addition, samples prepared from a stabilizer and fresh butter with no additions served as positive controls $\left(\mathrm{K}_{+}\right)$.

\subsection{Elucidation of Oxidative and Hydrolytic Stability of Butter}

In order to determine butter stability, compounds that reacted with thiobarbituric acid (TBARS) and total acid number (TAN) were analysed. TBARS were detected using the method described by Buege and Aust [16] and were expressed as $\mu \mathrm{mol}$ of malondialdehyde (MDA) released from $100 \mathrm{~g}$ of butter. TAN was determined by titration of butter samples with $0.1 \mathrm{M} \mathrm{KOH}$ in ethanol and was expressed as mmol of free fatty acids (FFA) per $100 \mathrm{~g}$ of butter.

The concentration of FFA was determined by the HPLC method as described by Fliszar [17] and expressed as mmol of FFA per $100 \mathrm{~g}$ of butter. Standards of lauric acid, myristic acid, oleic acid, palmitic acid, stearic acid and butter extract were filtered $(0.45 \mu \mathrm{m})$ and injected $(20$ $\mu \mathrm{l})$ into a LUNA $5 \mu \mathrm{m}$ C18(2) $(250 \times 4.6 \mathrm{~mm})$ chromatographic column. The column temperature was maintained at $40{ }^{\circ} \mathrm{C}$, the flow rate was $1 \mathrm{ml}$ per minute and detection was performed at $220 \mathrm{~nm}$. Liquids were filtered and degassed. A gradient of acetonitrile (ACN) and o-phosphoric acid $(0.1 \%)$ was employed to achieve suitable separation. The linear gradient used was as follows: $30 \% \rightarrow 75 \%$ of ACN from 0 to $10 \mathrm{~min} ; 75 \% \rightarrow 80 \%$ of ACN from 10 to $20 \mathrm{~min} ; 88 \% \rightarrow 99 \%$ of ACN from 20 to $22 \mathrm{~min}$; then held for $23 \mathrm{~min}$. An equilibration time of 5 min was employed between injections.

\subsection{Statistical Analysis}

Data were analysed using Statgraphics Plus for Windows. Results were compared with multifactor ANOVA and significant differences were determined using the LSD test at $\mathrm{p}<0.05$.

\section{RESULTS AND DISCUSSIONS}

\subsection{Thermal Modification of Catechin Preparations}

The differences in total catechin content among the HMC1, HMC2 and NMC preparations were not significant (Table 1). In the NMC preparation (-) form catechins $(2 \mathrm{~S}, 3 \mathrm{R})$ constituted approximately $10 \%$ of the total catechins. As a consequence of thermal modification of the preparation the amount of (-) forms $(2 \mathrm{~S}, 3 \mathrm{R})$ in HMC1 and HMC2 increased to 20 and $30 \%$ of total catechins, respectively. It is known that high temperatures cause $\gamma$-pyran ring opening, which enables rotation of the group situated at position $\mathrm{C} 2$ of the ring and a change in its locaion in relation to the plane of the whole molecule. The (-) forms (2S, 3R) in which the groups at the asymmetric carbon atoms are in trans orientation to each other are more stable than their (-) epiforms (2R, 3R) [7]. The rate of epimerization depends not only on the temperature and on the time of exposure but also on the presence of metal ions and the $\mathrm{pH}$ of the solution $[8,18]$.

\subsection{Oxidative Stability of Butter Enriched with Catechins}

During storage under refrigeration $\left(8{ }^{\circ} \mathrm{C}\right)$ all catechin preparations inhibited butter oxidation to an extent that did not differ from the positive control (Table 2). $\delta$-Tocopherol and BHT, however, were less effective stabilizers, although the amounts of MDA assayed in butter samples stabilized with these agents were $39.2 \%$ and $88 \%$ lower, respectively, in comparison to samples without stabilizer stored at $8{ }^{\circ} \mathrm{C}$ for 14 days (negative control, K-).

The amount of MDA assayed in butter samples stored at $-20{ }^{\circ} \mathrm{C}$ for four weeks corresponded with the amount of MDA in the positive control for samples stabilized with the NMC and HMC1 preparations. On the other hand, the amount of MDA in samples stabilized with the HMC2 preparation, $\delta$-tocopherol and BHT did not differ from the 
Table 1. The percentage of catechins ((-) EGCG, (-) ECG, (-) EC, (-) GCG, (-) CG, (-) C) and GA gallic acid) in a dry mass of thermally modified (HMC1, HMC2) and non-modified (NMC) catechin preparations. Different superscripts within a column indicate significant differences between catechin preparations $($ at $\mathrm{p}<0.05)$. All analyses were carried out in quadruplicate.

\begin{tabular}{|c|c|c|c|c|c|c|c|c|}
\hline \multirow{2}{*}{ Catechin preparations } & \multirow[b]{2}{*}{ GA } & \multicolumn{3}{|c|}{ (-) epiform (2R, 3R) [\% d.m] } & \multicolumn{3}{|c|}{ (-) form $(2 S, 3 R)$ [\% d.m.] } & \multirow{2}{*}{ Total catechins } \\
\hline & & (-) EGCG & (-) ECG & $(-) \mathrm{EC}$ & (-) GCG & $(-) C G$ & $(-) \mathrm{C}$ & \\
\hline NMC & $0.24^{\mathrm{a}}$ & $49.88^{c}$ & $11.30^{\mathrm{b}}$ & $7.02^{b}$ & $4.20^{\mathrm{a}}$ & $1.63^{\mathrm{a}}$ & $1.64^{\mathrm{a}}$ & $75.92^{\mathrm{a}}$ \\
\hline HMC1 & $0.35^{\mathrm{b}}$ & $45.10^{\mathrm{b}}$ & $9.78^{\mathrm{a}}$ & $5.93^{\mathrm{a}}$ & $8.53^{\mathrm{b}}$ & $3.03^{\mathrm{b}}$ & $3.10^{\mathrm{b}}$ & $75.91^{\mathrm{a}}$ \\
\hline HMC2 & $0.47^{\mathrm{c}}$ & $36.04^{\mathrm{a}}$ & $9.62^{\mathrm{a}}$ & $5.42^{\mathrm{a}}$ & $16.04^{\mathrm{c}}$ & $3.95^{\mathrm{c}}$ & $4.48^{\mathrm{c}}$ & $76.03^{\mathrm{a}}$ \\
\hline
\end{tabular}

Table 2. Concentrations of MDA assayed in $100 \mathrm{~g}$ of butter. All stabilizers were added at doses of $50 \mathrm{mg}$ per $100 \mathrm{~g}$ of butter. Different superscripts within a row indicate significant differences between samples (at $\mathrm{p}<0.05)$. All analyses were carried out in quadruplicate. $\mathrm{HMC} 1, \mathrm{HMC} 2$ = thermally modified catechin preparations. $\mathrm{NMC}=$ non-modified catechin preparation. $\mathrm{K}_{+}$denotes the amount of MDA in fresh butter.

\begin{tabular}{|c|c|c|c|c|c|c|c|}
\hline \multirow{3}{*}{$\begin{array}{l}\text { Thermal } \\
\text { treatment }\end{array}$} & \multicolumn{7}{|c|}{ MDA $\mu \mathrm{mol} / 100 \mathrm{~g}$ butter } \\
\hline & \multicolumn{5}{|c|}{ Butter stabilizers } & \multicolumn{2}{|c|}{ Butter without stabilizer } \\
\hline & NMC & HMC1 & HMC2 & $\begin{array}{c}\delta \text {-Tocophero } \\
\text { I }\end{array}$ & BHT & $\mathbf{K}_{+}$ & $\mathbf{K}$ \\
\hline $\begin{array}{l}\text { Refrigeration } \\
8^{\circ} \mathrm{C}, 2 \text { weeks }\end{array}$ & $0.84^{\mathrm{a}}$ & $0.85^{\mathrm{a}}$ & $0.86^{\mathrm{a}}$ & $3.66^{\mathrm{c}}$ & $1.34^{\mathrm{b}}$ & $0.77^{\mathrm{a}}$ & $5.52^{\mathrm{d}}$ \\
\hline $\begin{array}{c}\text { Freezing } \\
-20^{\circ} \mathrm{C}, 4 \text { weeks }\end{array}$ & $0.82^{\mathrm{a}}$ & $0.77^{\mathrm{a}}$ & $1.12^{\mathrm{b}}$ & $1.19^{\mathrm{b}}$ & $1.21^{\mathrm{b}}$ & $0.77^{\mathrm{a}}$ & $1.20^{\mathrm{b}}$ \\
\hline $\begin{array}{c}\text { Heating } \\
50^{\circ} \mathrm{C}, 1 \mathrm{~h}\end{array}$ & $1.05^{\mathrm{cd}}$ & $0.85^{\mathrm{a}}$ & $0.96^{\mathrm{b}}$ & $1.11^{\mathrm{d}}$ & $1.02^{\mathrm{bc}}$ & $0.77^{\mathrm{a}}$ & $1.30^{\mathrm{e}}$ \\
\hline $\begin{array}{l}\text { Heating } \\
100^{\circ} \mathrm{C}, 1 \mathrm{~h}\end{array}$ & $1.08^{\mathrm{b}}$ & $1.18^{\mathrm{b}}$ & $1.20^{\mathrm{b}}$ & $1.62^{\mathrm{c}}$ & $1.25^{\mathrm{b}}$ & $0.77^{\mathrm{a}}$ & $1.67^{\mathrm{c}}$ \\
\hline
\end{tabular}

Table 3. Concentrations of FFA assayed in $100 \mathrm{~g}$ of butter. All stabilizers were added at doses of $50 \mathrm{mg}$ per $100 \mathrm{~g}$ of butter. Different superscripts within a row indicate significant differences between samples (at $\mathrm{p}<0.05$ ). Mean values from four independently performed experiments. HMC1, HMC2 = thermally modified catechin preparations. NMC = non-modified catechin preparation. $\mathrm{K}_{+}$ denotes the amount of MDA in fresh butter.

\begin{tabular}{|c|c|c|c|c|c|c|c|}
\hline \multirow{3}{*}{$\begin{array}{l}\text { Thermal } \\
\text { treatment }\end{array}$} & \multicolumn{7}{|c|}{ FFA mmol/100 g butter } \\
\hline & \multicolumn{4}{|c|}{ Butter stabilizers } & \multicolumn{3}{|c|}{ Butter without stabilizer } \\
\hline & NMC & HMC1 & HMC2 & $\delta$-Tocopherol & BHT & $\mathbf{K}_{+}$ & $\mathbf{K}$. \\
\hline $\begin{array}{l}\text { Refrigeration } \\
8^{\circ} \mathrm{C}, 2 \text { weeks }\end{array}$ & $14.17^{\text {cd }}$ & $13.72^{\mathrm{bc}}$ & $13.58^{\mathrm{b}}$ & $14.85^{\mathrm{e}}$ & $15.00^{\mathrm{e}}$ & $4.19^{\mathrm{a}}$ & $14.67^{\mathrm{de}}$ \\
\hline $\begin{array}{c}\text { Freezing } \\
-20{ }^{\circ} \mathrm{C}, 4 \text { weeks }\end{array}$ & $4,15^{\mathrm{a}}$ & $4.51^{\mathrm{a}}$ & $4.42^{\mathrm{a}}$ & $4.46^{\mathrm{a}}$ & $4.17^{\mathrm{a}}$ & $4.19^{\mathrm{a}}$ & $4.15^{\mathrm{a}}$ \\
\hline $\begin{array}{l}\text { Heating } \\
50^{\circ} \mathrm{C}, 1 \mathrm{~h}\end{array}$ & $4.24^{\mathrm{a}}$ & $4.30^{\mathrm{a}}$ & $4.42^{\mathrm{a}}$ & $4.28^{\mathrm{a}}$ & $4.21^{\mathrm{a}}$ & $4.19^{\mathrm{a}}$ & $4.38^{\mathrm{a}}$ \\
\hline $\begin{array}{c}\text { Heating } \\
100{ }^{\circ} \mathrm{C}, 1 \mathrm{~h}\end{array}$ & $4.33^{\mathrm{a}}$ & $4.35^{\mathrm{a}}$ & $4.28^{\mathrm{a}}$ & $4.15^{\mathrm{a}}$ & $4.24^{\mathrm{a}}$ & $4.19^{\mathrm{a}}$ & $4.42^{\mathrm{a}}$ \\
\hline
\end{tabular}

negative control.

Butter samples stabilized with the HMC1 preparation incubated at $50{ }^{\circ} \mathrm{C}$ did not show any changes in the amounts of TBARS compared to the fresh butter $\left(\mathrm{K}_{+}\right)$. In the conditions of the assay only the HMC1 preparation effectively stopped the oxidation process. On the other hand, $\delta$-tocopherol was the least efficient butter stabilizer (35.9\% less MDA generated during incubation than in the negative control K.). Analysis of the results obtained for samples incubated at $100{ }^{\circ} \mathrm{C}$ did not demonstrate any differences between the extent of oxidation of butter stabilized with catechin preparations of various amounts of (-) forms (2S, 3R) and BHT. These stabilizers limited the amounts of oxidation products emerging during heating at $100{ }^{\circ} \mathrm{C}$ by 46.7 up to $65.6 \%$ compared to the negative control. As in the case of incubation at $50{ }^{\circ} \mathrm{C}$, $\delta$-tocopherol was the least efficient stabilizer because no differences were observed between butter stabilized with 
$\delta$-tocopherol and the negative control. Neither of the preparations used at a rate of $50 \mathrm{mg}$ per $100 \mathrm{~g}$ of butter stopped the oxidation of butter heated at $100{ }^{\circ} \mathrm{C}$. In order to establish whether any of the catechin preparations were capable of stopping the butter oxidation process at the level corresponding to the positive control at $100{ }^{\circ} \mathrm{C}$, higher doses of preparations were used (Figure 1).

At doses of up to $100 \mathrm{mg}$ of catechins per $100 \mathrm{~g}$ of butter, the efficacies of all preparations tested were similar. For doses higher than $100 \mathrm{mg}$ of catechins per $100 \mathrm{~g}$ of butter, the HMC1 preparation containing $20 \%$ of (-) forms $(2 \mathrm{~S}, 3 \mathrm{R})$ proved to be the most effective stabilizer. $\mathrm{HMC} 1$ stopped the oxidation process at the level corresponding to the positive control at a dose of $400 \mathrm{mg}$ per $100 \mathrm{~g}$ of butter. The least effective was the HMC2 preparation with the highest proportion of (-) forms (2S, $3 R)$. Increasing the concentration from 200 to $400 \mathrm{mg}$ per $100 \mathrm{~g}$ of butter did not decrease the rate of oxidation during a one-hour incubation of butter at $100{ }^{\circ} \mathrm{C}$.

Experiments determining the efficacy of non-modified green tea catechins as stabilizers in poultry meat [19], beef [20,21], pork [22], fish [21] and vegetable oils [23] have been reported. O'Sullivan and co-workers [19] showed that catechins increase the durability of meat under conditions of refrigeration through inhibition of the oxidation process, but not as efficiently as BHT. However, Chen [23] showed that catechins stopped oxidation more efficiently than BHT in oil heated to $95^{\circ} \mathrm{C}$. These results suggest that the (-) forms $(2 \mathrm{~S}, 3 \mathrm{R})$ that emerge following heating demonstrate higher antioxidative activity than the stereoisomers classified as (-) epiforms $(2 \mathrm{~S}, 2 \mathrm{R})$. $\mathrm{Xu}$ and co-workers [24] demonstrated, however, that the highest difference, in favour of epiforms $(2 \mathrm{~S}, 2 \mathrm{R})$, occurs between (-) EGC and (-) GC whilst the other pairs of stereoisomers (-) $\mathrm{EGCG} \rightarrow(-)$ GCG; $(-) \mathrm{EC} \rightarrow(-) \mathrm{C}$; $(-) \mathrm{ECG} \rightarrow(-) \mathrm{CG}$ had a similar antioxidative activity. In our study the highest antioxidative activity in the HMC1 preparation, in which the proportion of stereoisomers classified as (-) forms (2S, 3R) amounted to $20 \%$, was probably due to the synergistic effect of both catechin stereoisomers. A decrease in the antioxidative activity of the HMC2 preparation (containing $30 \%$ of (-) forms (2S, $3 \mathrm{R})$ ) in samples exposed to 50 and $100{ }^{\circ} \mathrm{C}$ was most probably due to further conversions of the (-) forms ( $2 \mathrm{~S}$, $3 \mathrm{R})$ to polymeric structures typical for fermented teas.

\subsection{Hydrolytic Stability of Butter Enriched with Catechins}

Incubation of butter samples for one hour at $50{ }^{\circ} \mathrm{C}$ and $100{ }^{\circ} \mathrm{C}$ and further storage at $-20^{\circ} \mathrm{C}$ for four weeks did not increase the amount of FFA (Table 3).

Alterations in the amounts of FFA were observed only for butter samples stored at $8{ }^{\circ} \mathrm{C}$ for 14 days. When stabilizers were used at a level of $50 \mathrm{mg}$ per $100 \mathrm{~g}$ of butter, a decrease in the amounts of free fatty acids released as

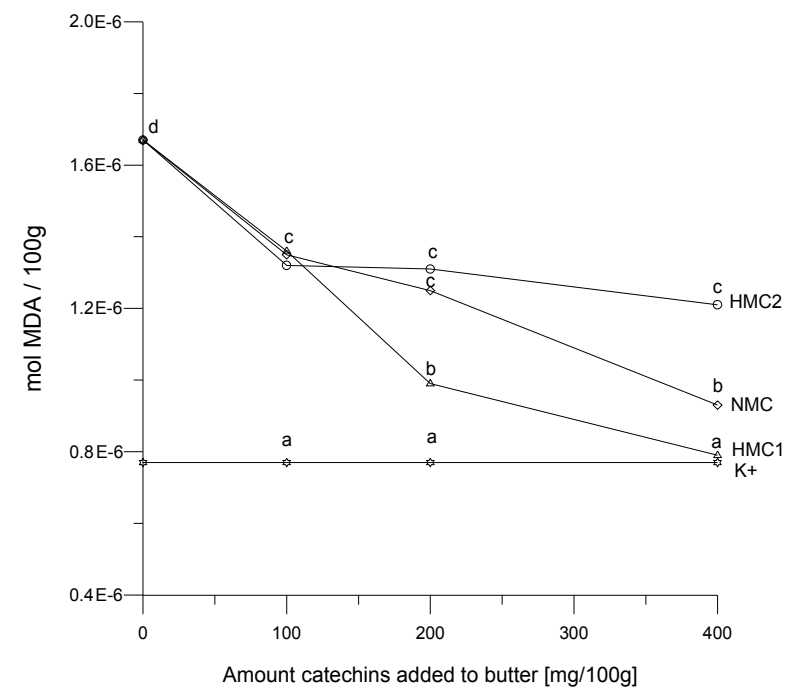

Figure 1. The influence of the concentration of catechin preparations (NMC, HMC1, HMC2) added to $100 \mathrm{~g}$ of butter on the amount of dimalonic aldehyde released during a one-hour incubation at $100{ }^{\circ} \mathrm{C}$. Individual letters denote statistically significant differences $($ at $\mathrm{p}<0.05)$. All analyses were carried out in quadruplicate. $\mathrm{K}_{+}$denotes the amount of MDA in fresh butter.

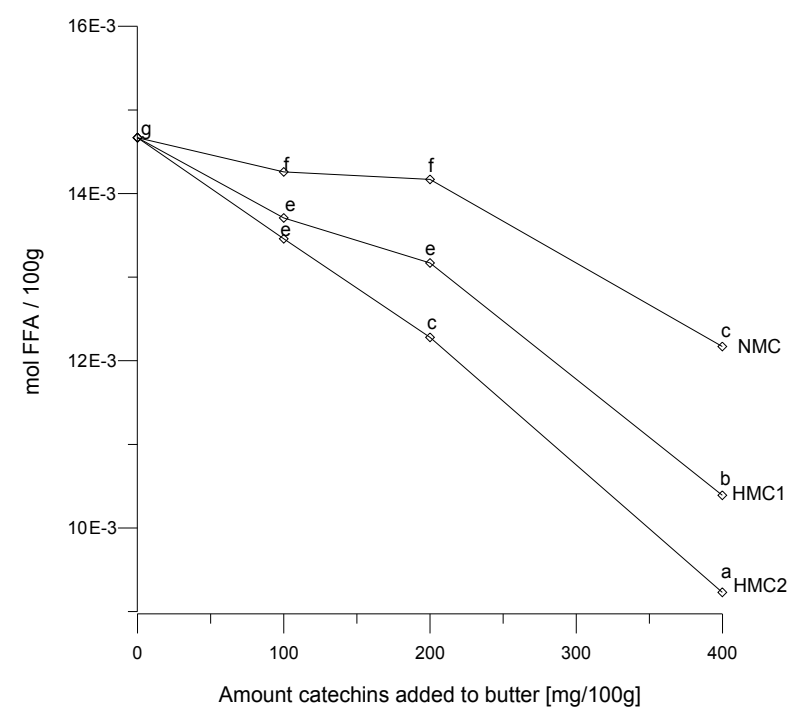

Figure 2. The influence of the concentration of catechin preparations (NMC, HMC1, HMC2) added to $100 \mathrm{~g}$ of butter on the amount of free fatty acids (FFA) released during two weeks storage at $8{ }^{\circ} \mathrm{C}$. Individual letters denote statistically significant differences (at $\mathrm{p}<0.05$ ). All analyses were carried out in quadruplicate.

compared to the negative control was observed only with thermally modified catechins. The other compounds did not influence the hydrolytic stability of butter. However, the amount of fatty acids was lower by only $13.3 \%$ for the HMC2 catechin preparation and by $10.9 \%$ for the HMC1 preparation in comparison to the negative control. In order to improve the hydrolytic stability of butter under refrigeration conditions $\left(8^{\circ} \mathrm{C}\right)$ the amounts of cate- 
chins added were increased (Figure 2).

With increasing dose and an increased proportion of catechins classified as (-) forms $(2 \mathrm{~S}, 3 \mathrm{R})$, the amount of free fatty acids decreased during storage at $8{ }^{\circ} \mathrm{C}$. For the HMC2 and HMC1 preparations at the highest dose the amounts of FFA were lower by $52.1 \%$ and $40.6 \%$ respectively, compared to the negative control. Inhibition of the hydrolysis of butter lipids is most probably a secondary effect caused by suppression of microbial growth. A number of data in the literature confirm the antiseptic activity of polyphenols, including catechins $[25,26]$.

In conclusion, catechin preparations were more efficient butter stabilizers than BHT and $\delta$-tocopherol. Thermal modification of the catechin preparation that led to the formation of $20 \%$ (-) forms (2S, 3R) improved its antioxidative efficacy; however, further increases in (-) form catechins $(2 \mathrm{~S}, 3 \mathrm{R})$ to $30 \%$ of these molecules led to a decrease in the antioxidative stability of butter. The hydrolytic stability of butter, on the other hand, increa- sed as the concentration of catechins classified as (-) forms (2S, 3R) increased.

\section{REFERENCES}

[1] S. Kuriyama, (2008) The relation between green tea consumption and cardiovascular disease as evidenced by epidemiological studies. American Society for Nutrition, 138, 1548S-1553S.

[2] S. M. Henning, W. Aronson, Y. Niu, F. Cande, N. H. Lee, N. P. Seeram, R-P. Lee, J. Lu, D. M. Harris, A. Moro, J. Hong, L. Pak-Shan, R. J. Bernard, H. G. Ziaee, G. Csathy, V. L. W. Go, H. Wang, D. Heber, (2006) Tea polyphenols and theaflavins are present in prostate tissue of humans and mice after green and black tea consumption. American Society for Nutrition, 136, 1839-1843.

[3] L. Arab and D. Il'yasova, (2003) The epidemiology of tea consumption and colorectal cancer incidence. The American Society for Nutritional Sciences, 133, 3310S- 3318S.

[4] M. P. Almajano, R. Carbo, A. J. L. Jimenez, M. H. Gordon, (2008) Antioxidant and antimicrobial activities of tea infusions, Food Chemistry, 108, 55-63.

[5] Y. Yoda, Z. Q. Hu, W. H. Zhao, T. Shimamura, (2004) Different susceptibilities of Staphylococcus and gramnegative rods to epigallocatechin gallate. Journal of Infection and Chemotherapy, 10, 55-58.

[6] H. Wang, G. J. Provan, and K. Helliwell, (2000) Tea flavonoids: their functions, utilization and analysis. Trends in Food Science and Technology, 11, 152-160.

[7] H. Wang and K. Helliwell, (2000) Epimerisation of catechins in green tea infusions. Food Chemistry, 70, 337-344.

[8] Q. J. Zhu, A. Zhang, D. Tsang, Y. Huang, Z. Y. Chen, (1997) Stability of green tea catechins. Journal of Agricultural and Food Chemistry, 45, 4624-4628.

[9] I. Ikeda, Y. Imasato, E. Sasaki, M. Nakayama, H. Nagao, T. Takeo, F. Yayabe, M. Sugano, (1992) Tea catechins decrease micellar solubility and intestinal absorption of cho- lesterol in rats. Biochimica et Biophysica Acta, 1127, 141-146.

[10] I. Ikeda, M. Kobayashi, T. Hamada, K. Truda, H. Goto, K. Imaizumi, A. Nozawa, A. Sugimoto, T. Kakuda, (2003) Heat-epimerized tea catechins rich in gallocatechin gallate and catechin gallate are more effective to inhibit cholesterol absorption then tea catechins rich in epigallocatechin gallate and epicatechin gallate. Journal of Agricultural and Food Chemistry, 51, 7303-7307.

[11] Q. He, Y. Lv, K. Yao, (2007) Effects of tea polyphenols on the activities of $\alpha$-amylase, pepsin, trypsin and lipase. Food Chemistry, 101, 1178-1182.

[12] I. Ikeda, K. Truda, Y. Suzuki, M. Kobayashi, T. Unno, H. Tomoyori, H. Goto, Y. Kawata, K. Imaizumi, A. Nozawa, T. Kakuda, (2005) Tea catechins with gallolyl moiety suppress postprandial hypetriacyloglycerolemia by delaying lymphatic transport of dietary fat in rats. Journal Nutrition, 135, 155-159.

[13] O. Kajimoto, M. Yabune, T. Nakamura, K. Kotani, Y. Suzuki, A. Nozawa, K. Nagata, T. Unno, (2005) Tea catechins with gallolyl moiety reduce body weight and fat. Journal of Health Science, 1 (2), 161-171.

[14] M. Mika, A. Wikiera, K. Żyła, (2008) Effects of nonfermented tea extracts on in vitro digestive hydrolysis of lipids and on cholesterol precipitation. European Food Research and Technology, 4(226), 731-736.

[15] J. K. Lin, C. L. Lin, Y. C. Liang, S. Y. Lin-Shiau, and I. M. Juan, (1998) Survey of catechins, gallic acid, and methylxanthines in green, oolong, puerh, and black teas. Journal of Agricultural and Food Chemistry, 46, 3635-3642.

[16] J.A. Buege, and S.D. Aust, (1978) Microsomal lipid peroxidation. Methods in Enzymology, 52, 302-304.

[17] K. A. Fliszar, W. P. Wuelfing, Z. Li, and R. A. Reed, (2006) Profiling of medium chain glycerides used in pharmaceutical formulation development by reversed-phase HPLC. Journal of Pharmaceutical and Biomedical Analysis, 40, 896-900.

[18] Z. Y. Chen, Q. J. Zhu, D. Tsang, Y. Huang, (2001) Degradation of green tea catechins in tea drinks. Journal of Agricultural and Food Chemistry, 49, 477-482.

[19] C. M. O'Sullivan, A. M. Lynch, P. B. Lynch, D. S. Buckley, J. P. Kerry, (2004) Assessment of the antioxidant potential of food ingredients in fresh, previously frozen and cooked chicken patties. International Journal of Poultry Science, 3 (5), 337-344.

[20] M. Mitsumoto, M. N. O'Grady, J. P. Kerry, and D. J. Buckley, (2005) Addition of tea catechins and vitamin C on sensory evaluation, colour and lipid stability during chilled storage in cooked or raw beef and chicken patties. Meat Science, 69, 773-779.

[21] S. Tang, J. P. Kerry, D. Sheehan, D. J. Buckley, P. A. Morrissey, (2001) Antioxidative effect of added tea catechins on susceptibility of cooked red meat, poultry and fish patties to lipid oxidation. Food Research International, 34, 651-657.

[22] T. L. McCathy, J. P. Kerry, J. F. Kerry, P. B. Lynch, D. J. Buckley, (2001) Assessment of the antioxidant potential of natural food and plant extracts in fresh and previously frozen pork patties. Meat Science, 57, 177-184.

[23] Z. Y. Chen and P. T. Chan, (1996) Antioxidative activity of green tea catechins in canola oil. Chemistry and Physics of Lipids, 82, 163-172.

[24] J. Z. Xu, S. Y. V. Yeung, Q. Chang, Y. Huang, and Z. Y. Chen, (2004) Comparison of antioxidant activity and bioavailability of tea epicatechins with their epimers. British Journal of Nutrition, 91, 873-881.

[25] K.-T. Chung, C. Wei, and M. G. Johnson, (1998) Are tannins a double-edged sword in biology and health? Trends Food Sci. Tech., 9, 168-175.

[26] Y. Yilmaz, (2006) Novel uses of catechins in food. Trends Food Sci. Tech., 17, 64-71. 